BEST PRACTICE

\title{
Subclinical hyperthyroidism: to treat or not to treat?
}

\author{
E H Hoogendoorn, M den Heijer, A P J van Dijk, A R Hermus
}

Postgrad Med J 2004;80:394-398. doi: 10.1136/pgmj.2003.017095

Subclinical hyperthyroidism may be defined as the presence of free thyroxine and tri-iodothyronine levels within the reference range and a reduced serum thyroid stimulating hormone (TSH) level. In this review the prevalence of low TSH in the population and health consequences of subclinical hyperthyroidism, for example, effects on heart and bone mass, are discussed. Guidelines for treatment are given, based on expert opinion.

See end of article for authors' affiliations

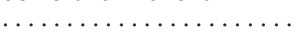

Correspondence to: Dr E H Hoogendoorn, Department of Endocrinology, University Medical Center Nijmegen, PO Box 9101, $6500 \mathrm{HB}$

Nijmegen,

The Netherlands;

e.hoogendoorn@

endo.umen.nl

Submitted

13 November 2003

Accepted 7 January 2004
S ubclinical hyperthyroidism may be defined as the presence of free thyroxine and triiodothyronine levels within the reference range and a reduced serum thyroid stimulating hormone (TSH) level. The cause is either exogenous thyroid hormone therapy or endogenous overproduction of thyroxine and/or triiodothyronine. Subclinical hyperthyroidism has to be differentiated from other causes of low serum TSH levels, such as non-thyroidal illness or the use of TSH suppressing medication other than thyroid hormone (for example, glucocorticoids, dopamine). ${ }^{1}$ Exogenous subclinical hyperthyroidism can be due to overzealous thyroid hormone replacement therapy or intentional suppressive thyroid hormone therapy, as in patients with thyroid cancer, thyroid nodules, or goitre. In endogenous subclinical hyperthyroidism, the source of the mild excess of thyroid hormone in the circulation is the thyroid itself, as in Graves' disease, multinodular goitre, solitary functioning thyroid nodules, or thyroiditis. Iatrogenic subclinical hyperthyroidism may not be the same condition as endogenous subclinical hyperthyroidism, but there is no clear evidence supporting this statement.

With the easy availability of sensitive TSH assays in the last decades, the diagnosis subclinical hyperthyroidism is made more often. ${ }^{2}$ An absence of symptoms was once part of the definition but we now understand that subtle symptoms or signs of thyrotoxicosis may be present. $^{3}$ There seems to be an individual set point for thyroid hormone values in each individual. ${ }^{4}$ TSH outside the reference range is likely to indicate that tri-iodothyronine and thyroxine levels are not normal for that particular person. Due to the log linear negative feedback relationship between serum thyroid hormone and TSH, even a small increase in serum thyroid hormone can suppress TSH secretion. Whether there is a difference between patients with a low, but detectable TSH versus patients with a fully suppressed TSH is unclear.

\section{PREVALENCE OF LOW TSH IN THE POPULATION}

Bagchi et al found serum TSH values $<0.1 \mathrm{mU} / \mathrm{l}$ in $2.5 \%$ of 968 United States citizens over age 55, two thirds of whom were taking thyroid hormone preparations. ${ }^{5}$ In the original Framingham Heart Study cohort-2575 ambulatory persons older than 60 years-3.9\% had a serum TSH $<0.1 \mathrm{mU} / \mathrm{l}$, and about half of them were taking thyroid hormone. Overt hyperthyroidism was only found in $0.2 \%{ }^{6}$ In a cross sectional study, conducted in 1995 in Colorado with 25862 participants, TSH levels $<0.3 \mathrm{mU} / \mathrm{l}$ were found in $2.1 \%$ of people over 18 years of age, in $1.3 \%$ due to thyroid hormone use. One out of five patients treated with thyroid hormone showed suppression of TSH. ${ }^{7}$ The third National Health and Nutrition Examination Survey in the United States from 1988 to 1994 found TSH levels $<0.1 \mathrm{mU} / \mathrm{l}$ and normal thyroxine $(<169.9 \mathrm{nmol} / \mathrm{l})$ in $0.7 \%$ of people over 12 years of age. ${ }^{8}$ In the subgroup of 820 persons self reporting thyroid disease or taking thyroid medications, $10.9 \%$ had subclinical hyperthyroidism. In a cross sectional survey in a previously iodine deficient area of Germany thyroid function was measured in 3941 participants without known thyroid disease between the ages of 20 and 79 years. A TSH $<0.3 \mathrm{mU} / \mathrm{l}$ was found in $11.3 \%{ }^{9} \quad$ Subclinical hyperthyroidism (TSH $<0.1 \mathrm{mU} / \mathrm{l}$ and normal serum free thyroxine and free tri-iodothyronine levels) was found in $1.8 \%$, distributed similarly among women and men, but age dependent with higher percentages in the older decades. In conclusion, the prevalence of subclinical hyperthyroidism varies depending on the criteria used and is age dependent (table 1).

There are few data on the follow up of thyroid function in patients with suppressed TSH levels. It is important to know that not infrequently on retesting some time later, TSH levels have returned to normal. For instance, Parle et al followed up 66 patients with TSH results below normal found in a cohort of 1193 subjects aged over 60 years, not taking thyroid medication. Of the 50 subjects with a TSH level between 0.05 and $0.5 \mathrm{mU} / \mathrm{l}$ at initial testing, $38(76 \%)$ returned to normal at 12 months; of those 16 with a TSH level $<0.05 \mathrm{mU} / \mathrm{l}, 14(87.5 \%)$ remained low at 12 months. Only one subject (who had an undetectable TSH) developed overt hyperthyroidism. ${ }^{10}$ Besides that seven of those with a low TSH level were using oral glucocorticoids-a known cause of suppression of TSH-it is likely that non-thyroidal illness, instead of subclinical

Abbreviations: BMD, bone mineral density; TSH, thyroid stimulating hormone 
Table 1 Prevalence of a suppressed serum TSH level in community based surveys. The studies by Parle et al ${ }^{10}$ are based on the same cohort

\begin{tabular}{|c|c|c|c|c|c|c|c|}
\hline Author & Year & $\begin{array}{l}\text { No of } \\
\text { subjects }\end{array}$ & $\begin{array}{l}\text { Age } \\
\text { (years) }\end{array}$ & $\begin{array}{l}\text { Cut off value } \\
(\mathrm{mU} / \mathrm{l})\end{array}$ & $\begin{array}{l}\% \text { TSH } \\
\text { suppressed }\end{array}$ & $\begin{array}{l}\% \text { Overtly } \\
\text { hyperthyroid }\end{array}$ & $\begin{array}{l}\% \text { Thyroid } \\
\text { hormone use }\end{array}$ \\
\hline Bagchi et $a^{5}$ & 1990 & 986 & 55-92 & $<0.1$ & 2.5 & $?$ & 1.7 \\
\hline Parle et al ${ }^{10}$ & 1991 & 1210 & $>60$ & $<0.5$ & $\begin{array}{l}\text { Male } 5.5 \text {; } \\
\text { female } 6.3\end{array}$ & $?$ & 0.0 \\
\hline Sawin et $a^{\beta}$ & 1991 & 2575 & $>60$ & $<0.1$ & 3.9 & 0.2 & 2.0 \\
\hline Canaris et al & 2000 & 25862 & $>18$ & $<0.3$ & 2.2 & 0.1 & 1.3 \\
\hline Parle et $a l^{14}$ & 2001 & 1191 & $>60$ & $<0.1$ & 1.7 & 0.1 & 0.0 \\
\hline Hollowel et $a^{\beta}$ & 2002 & 17353 & $>12$ & $<0.1$ & 1.2 & 0.5 & $?$ \\
\hline \multirow[t]{2}{*}{ Volzke et $a^{p}$} & 2003 & 3941 & $20-79$ & $<0.3$ & 11.3 & 0.4 & 0.0 \\
\hline & & & & $<0.1$ & 2.2 & & \\
\hline
\end{tabular}

hyperthyroidism, was responsible for a number of the mildly decreased TSH values in this study.

In endogenous subclinical hyperthyroidism due to multinodular goitre, there seems to be a pattern of slow progression towards overt hyperthyroidism. In a Dutch study of 90 patients with euthyroid multinodular goitre, mainly women with a mean age of 55 years, eight became hyperthyroid within seven years and all of them had autonomous function before becoming hyperthyroid. ${ }^{11}$ Faber et al followed up 12 women with subclinical hyperthyroidism due to multinodular goitre, median age 62 years, for two years, and none of them became overtly hyperthyroid nor euthyroid during that time. ${ }^{12}$

\section{HEALTH CONSEQUENCES OF SUBCLINICAL HYPERTHYROIDISM}

The influence of subclinical hyperthyroidism on health is not yet clear. Evidence is accumulating that it has important clinical effects. ${ }^{13}$ The most prominent physical consequences seem to be adverse effects on cardiac function, most significantly a higher incidence of atrial fibrillation and a decrease in bone density (particularly of cortical bone). Furthermore, it is debated whether subclinical hyperthyroidism is associated with excess mortality. In a population based study in the United Kingdom among 1191 people older than 60 years not receiving thyroid hormone or antithyroid therapy, $1.7 \%$ had TSH concentrations less than $0.1 \mathrm{mU} / \mathrm{l}$, and $4.3 \%$ had concentrations between 0.1 and $0.5 \mathrm{mU} /{ }^{14}$ Mortality from all causes was significantly higher at years 2 , 3,4 , and 5 (hazard ratios $2.1,2.2,1.8$, and 1.8 , respectively), but not at the end of the study (hazard ratio 1,2), in the subjects with suppressed TSH. ${ }^{14}$ Most of the increased mortality was due to cardiovascular disease. However, these data should be viewed cautiously, because, as mentioned before, in a number of subjects low serum TSH concentrations may have been caused by non-thyroidal illness or use of TSH suppressing medication instead of subclinical hyperthyroidism.

\section{Effects on the heart}

Overt hyperthyroidism causes palpitations, with some degree of exercise impairment and a widened pulse pressure, resulting from both an increase in sympathetic tone and a decrease in parasympathetic tone, combined with direct effects of thyroid hormone on cardiac muscle. ${ }^{15}$ It can induce significant cardiac dysfunction, for example atrial fibrillation and heart failure. ${ }^{16}$ Most patients who develop heart failure during hyperthyroidism have intrinsic cardiac disease, but also thyrotoxic persons without underlying heart disease can develop so-called rate related heart failure.

Whether subclinical hyperthyroidism can also induce cardiac dysfunction is less clear. Biondi et al found more atrial premature beats and a $20 \%$ higher mean heart rate in
20 relatively young patients with iatrogenic subclinical hyperthyroidism, compared with controls. In addition, echocardiographic measurements showed evidence of left ventricular hypertrophy in six of 20 patients. ${ }^{17}$ Reduced exercise tolerance, diastolic dysfunction, and impaired systolic function during exercise are other findings in a group of 10 subjects, all of whom had been treated with TSH suppressive doses of L-thyroxine for at least five years and all of whom complained of exertional dyspnoea. ${ }^{18}$ Both myocardial hypertrophy and diastolic dysfunction improved after treatment with $\beta$-blocking agents. ${ }^{19} 20$ Six months of individual tailoring of the TSH suppressive L-thyroxine dose aiming at a TSH of $0.1 \mathrm{mU} / \mathrm{l}$ was associated with normalisation of echocardiographic parameters and an increase in maximal workload. ${ }^{21}$ In contrast to these studies, Shapiro et al found hardly any cardiac effects in 17 patients chronically treated with TSH-suppressive doses of L-thyroxine. ${ }^{22}$ All studies mentioned above were done in patients with a TSH level $<0.1 \mathrm{mU} / \mathrm{l}$. However, it should be noted that Shapiro et al studied patients only minimally different from controls with respect to results of a symptom score questionnaire, while Biondi et al and Mercuro et al studied patients who had a clear increase in symptom scores.

There is little known about the effects of endogenous subclinical hyperthyroidism on the heart. Biondi et al demonstrated an increase of left ventricular mass, more specifically an increase of septal and posterior wall thickness, enhanced resting systolic function and significantly impaired Doppler parameters of diastolic function in relatively young patients (mean age 43 years). ${ }^{23}$ Two small recent studies suggest a beneficial effect of treatment of subclinical hyperthyroidism on cardiac function. Faber et al treated six elderly women with subclinical hyperthyroidism due to multinodular goitre with radioiodine resulting in euthyroidism and found a significant reduction in heart rate, cardiac output and an increase in systolic vascular resistance. ${ }^{24}$ Sgarbi et al treated 10 patients, median age 59 years, with endogenous subclinical hyperthyroidism due to a multinodular goitre $(\mathrm{n}=5)$, a solitary functioning thyroid nodule $(\mathrm{n}=2)$, or a diffuse goitre $(\mathrm{n}=3)$ for six months with antithyroid therapy. ${ }^{25}$ After reaching euthyroidism they found a significant decrease in heart rate and in the number of atrial and ventricular premature beats. Echocardiography demonstrated a reduction of the left ventricular mass index, interventricular septum thickness, and left ventricular posterior wall thickness at diastole.

A major concern is that subclinical hyperthyroidism is associated with an increased incidence of atrial fibrillation. It is well known that overt hyperthyroidism is associated with atrial fibrillation: atrial fibrillation occurs in approximately $15 \%$ of all thyrotoxic patients and hyperthyroidism accounts for $15 \%$ of all patients with newly diagnosed atrial fibrillation. ${ }^{26}$ Tenerz et al followed up 40 patients, mainly women 
with a mean age of 65 years, with subclinical thyrotoxicosis (TSH below $0.1 \mathrm{mU} / \mathrm{l}$ ) mostly due to multinodular goitre for two years. They found that atrial fibrillation was present in $28 \%$ of the patients (in eight patients at the start of the study and in three more after two years) compared with $10 \%$ of the controls (four at the start and no new cases during follow up). ${ }^{27}$ Researchers from the Framingham Heart Study followed 2007 subjects over 60 years of age for 10 years. ${ }^{28}$ The cumulative incidence of atrial fibrillation varied with the serum TSH concentration: it was $28 \%$ in those with serum TSH values $<0.1 \mathrm{mU} / \mathrm{l}, 16 \%$ in those with values between 0.1 and $0.4 \mathrm{mU} / \mathrm{l}$, and $11 \%$ in those with normal TSH values. Only two of the 13 patients with suppressed TSH values who developed atrial fibrillation also developed overt hyperthyroidism during the follow up period. In a large retrospective study by Auer et al the relative risk of atrial fibrillation in subjects with a TSH of $<0.4 \mathrm{mU} / \mathrm{l}$ and normal free thyroxine and tri-iodothyronine concentrations was 5.2 (95\% confidence interval 2.1 to 8.7), compared with those with normal concentrations of serum TSH. ${ }^{29}$ They also found that atrial fibrillation is as common in patients with subclinical hyperthyroidism $(12.7 \%)$ as in those with overt hyperthyroidism $(13.8 \%)$. Restoration of euthyroidism resulted in conversion to sinus rhythm in only $19 \%$ of patients with subclinical hyperthyroidism. There are no data available as to whether treatment of subclinical hyperthyroidism prevents the development of atrial fibrillation.

In conclusion, the majority of data suggest that thyroid hormone levels above the hypothalamic-pituitary set point have a negative effect on cardiac function and morphology. Furthermore, subclinical hyperthyroidism is associated with a significantly increased risk on atrial fibrillation.

\section{Effects on bone mass}

Overt hyperthyroidism is associated with increased bone resorption and, to a lesser extent, increased bone formation. The changes are more prominent in cortical bone (for example, wrist and hip) than in trabecular bone (for example, lumbar spine). ${ }^{30}$ Studies of the effects of exogenous subclinical hyperthyroidism on bone have provided conflicting results. Two large meta-analyses reached a similar conclusion, namely that TSH suppressive doses of Lthyroxine decrease bone mineral density (BMD) in postmenopausal but not in premenopausal women and in men. ${ }^{31}{ }^{32}$ Preserved oestrogen production is considered to protect against loss of bone mass in premenopausal women with suppressed TSH.

Endogenous subclinical hyperthyroidism seems to confer the same risks as suppressive L-thyroxine doses, although considerably fewer data are available. Mudde et al studied 23 women (six premenopausel and 17 postmenopausal) with subclinical hyperthyroidism due to untreated multinodular goitre. They found significantly lower bone densities at the forearm in patients than in age and menopausal status matched euthyroid controls. ${ }^{33}$ Treatment of subclinical hyperthyroidism has probably a beneficial effect on BMD, as demonstrated in two small studies. Mudde et al normalised serum TSH in eight subclinically hyperthyroid postmenopausal women by treating them with methimazole. After two years a cessation of further bone loss was demonstrated as measured over the distal forearm, compared with untreated controls. ${ }^{34}$ Faber et al treated 16 postmenopausal women with subclinical hyperthyroidism due to multinodular goitre in a non-randomised manner with radioiodine, and found unchanged BMD at the spine and hip two years later, while in contrast in the control group $(n=12)$ BMD showed a decline of $2 \%$ per year. $^{12}$

While overt hyperthyroidism is known to be associated with increased fracture risk, data are less clear for subclinical hyperthyroidism. ${ }^{35}$ A study on 1180 patients on thyroxine replacement therapy ( $90 \%$ female, $75 \%$ over 50 years of age) found no excess of fractures in patients with TSH $<0.05 \mathrm{mU} / \mathrm{l}$ compared to those with normal TSH levels. ${ }^{36}$ However, a large prospective study with a mean follow up of 3.7 years found that women over age 65 with a low TSH level $(<0.1 \mathrm{mU} / \mathrm{l})$ have a threefold increased risk for hip fracture and a fourfold increased risk for vertebral fracture compared with women who had normal TSH levels $(0.5-5.5 \mathrm{mU} / \mathrm{l}) .^{37}$ In the group with suppressed TSH, 86\% reported thyroid hormone use. Unfortunately, tri-iodothyronine and thyroxine were not measured in this study, so it is not clear how many of these women had overt compared with subclinical hyperthyroidism.

In conclusion, it seems that postmenopausal women with subclinical hyperthyroidism have a lower BMD but there is no firm evidence that there is an increased risk of fractures in this group.

\section{Quality of life, mood, and dementia}

Biondi et al have reported that relatively young patients with endogenous subclinical hyperthyroidism have impaired quality of life as assessed by the Short Form 36 Health Survey. ${ }^{23}$ In contrast, in a non-hospital setting, an improvement in mood has been reported by subclinically hyperthyroid workers of a chemical plant, taking part in a screening programme. ${ }^{38}$ Oomen et al determined thyroid function in all patients admitted to three psychiatric hospitals in the Netherlands between 1987 and 1990, and detected TSH levels $<0.4 \mathrm{mU} / \mathrm{l}$ in $4.1 \%$ (134/3316). They found that affective disorders (particularly depression in females and mania in males) were more prevalent in patients with a suppressed TSH level, most of whom had subclinical rather that overt hyperthyroidism. ${ }^{39}$ Since the number of subclinically hyperthyroid individuals in these studies was small, it is hard to draw firm conclusions on mood, affective disorders, or quality of life.

Interestingly, in a population based prospective study among 1846 persons over 55 years of age, 61.9\% females, it was found that subjects with serum TSH concentrations $<0.4 \mathrm{mU} / \mathrm{l}$ at baseline had a 3.5-fold increased risk of dementia during a 2-4 year follow up period. The risk of dementia was especially increased in subjects who were positive for antithyroid peroxidase antibodies. ${ }^{40}$ Further studies with a longer follow up period and a larger sample

\section{List of useful websites}

Information for doctors

- www.thyroid.org/professionals/publications/ guidelines.html

- www.guidelines.gov

- www.aace.com/clin/guidelines/hypo_hyper.pdf

- www.thyroidmanager.org

Information for patients

- www.thyroid.org/patients/index.html

- www.aace.com/members/brochures.php

- www.hormone.org/learn/thyroid.html

\section{Self help groups}

- www.thyroidfoundation.org

- www.btf-thyroid.org

- www.schildklier.nl (in Dutch) 


\section{Key references}

- Toft AD. Clinical practice. Subclinical hyperthyroidism. N Engl J Med 2001;345:512-16.

- Andersen S, Pedersen KM, Bruun NH, et al. Narrow individual variations in serum $T(4)$ and $T(3)$ in normal subjects: a clue to the understanding of subclinical thyroid disease. J Clin Endocrinol Metab 2002;87:1068-72.

- Biondi B, Palmieri EA, Lombardi G, et al. Effects of subclinical thyroid dysfunction on the heart. Ann Intern Med 2002;137:904-14.

- Parle JV, Maisonneuve P, Sheppard MC, et al. Prediction of all-cause and cardiovascular mortality in elderly people from one low serum thyrotropin result: a 10-year cohort study. Lancet 2001;358:8615.

- Aver J, Scheibner P, Mische T, et al. Subclinical hyperthyroidism as a risk factor for atrial fibrillation. Am Heart J 2001;142:838-42.

size are needed to confirm this finding and to investigate the mechanism behind this association.

\section{Guidelines for treatment}

Considering the evidence that exogenous subclinical hyperthyroidism may have adverse effects on heart and bone we agree with recommendations from the American Association of Clinical Endocrinologists stating that "in patients who are receiving levothyroxine for replacement therapy, the dose should be adjusted so serum TSH values range from 0.3 to $3.0 \mathrm{microIU} / \mathrm{ml}$. An exception is thyroid hormone replacement treatment after thyroidectomy for differentiated thyroid cancer, in which case a mildly to moderately suppressed TSH level is generally desirable" ${ }^{\prime 4}$ In the latter case we prescribe the lowest amount of thyroid hormone possible to obtain a TSH of $<0.1 \mathrm{mU} / \mathrm{l}$. In addition, some physicians treat hypofunctional thyroid nodules with levothyroxine in doses which induce suppression of the TSH level. The benefits of this therapy should be weighted against the side effects. ${ }^{42}$

In patients with a suppressed TSH level due to an endogenous cause, it should be confirmed the suppressed TSH level is persistent rather than transient. Of course, a nonthyroidal cause such as non-thyroidal illness, pregnancy, pituitary or hypothalamic insufficiency, or the use of TSH suppressing medication other than thyroid hormone has to be excluded. The American Association of Clinical Endocrinologists recommends to reassess the TSH level along with free thyroxine and tri-iodothyronine estimates after 24 months. We follow the same policy.

Clearly randomised clinical trials are needed to answer the question whether or not treatment of endogenous subclinical hyperthyroidism prevents cardiac problems, especially atrial fibrillation, and protects BMD. Two such trials are soon to be started, one in the Netherlands and one in the United Kingdom. Current practice is mainly based on expert opinion. Older British guidelines do not favour treatment of subclinical hyperthyroidism, stating it is debatable whether there is excess morbidity. ${ }^{43}$ Clinical guidelines from the American College of Physicians state that the potential benefits of treating subclinical hyperthyroidism are theoretical. ${ }^{44}$ The American Association of Clinical Endocrinologists guidelines state, "If a sustained TSH suppression $(<0.1 \mathrm{mU} / \mathrm{l})$ is established, then management should be based on an
Self test questions (true/false; answers at end of references)

- Q1. Multinodular goitre is the most common cause of subclinical hyperthyroidism.

- Q2. Subjects with low serum TSH and normal free thyroxine and tri-iodothyronine concentrations are more likely to get atrial fibrillation, compared with those with normal concentrations of serum TSH.

- Q3. Women over age 65 years with a low TSH level $(<0.1 \mathrm{mU} / \mathrm{l})$ have a threefold increased risk for hip fracture and a fourfold increased risk for vertebral fracture compared with women who have normal TSH levels (0.5 to $5.5 \mathrm{mU} / \mathrm{l})$.

- Q4. Exogenous subclinical hyperthyroidism should be prevented at all times.

- Q5. Subclinical hyperthyroidism is a main cause of dementia.

\section{Summary box}

Serum TSH $<0.1 \mathrm{mU} / \mathrm{I}$, free thyroxine and free triiodothyronine within reference range:

Is the patient taking thyroid hormone therapy?

- Yes. Adjust dose so serum TSH values range from 0.3 to $3.0 \mathrm{mU} / \mathrm{l}$ unless the patient is receiving thyroid hormone treatment after thyroidectomy for differentiated thyroid cancer, in which case the lowest amount of thyroid hormone possible to obtain a TSH of $<0.1 \mathrm{mU} / \mathrm{l}$ should be prescribed.

- No. Reassess TSH, free thyroxine, and free triiodothyronine values after 2-4 months and exclude other causes of low TSH (such as non-thyroidal illness or the use of TSH suppressing medication other than thyroid hormone (for example, glucocorticoids, dopamine). If TSH remains suppressed, consider treatment in patients with signs or symptoms of thyrotoxicosis, especially when atrial fibrillation or osteoporosis is present.

individual program. For example, patients with symptoms of hyperthyroidism, atrial fibrillation, or unexplained weight loss would be appropriate candidates for treatment. Women with osteopenia or osteoporosis should undergo assessment for treatment. In patients with multinodular goitre, treatment should be considered. The treatment options include antithyroid drugs or radioactive iodine" ${ }^{\prime 4}$.1 We agree with these guidelines. We prefer radioiodine therapy, but another option is antithyroid drug therapy. However, after discontinuation of antithyroid drugs, endogenous subclinical hyperthyroidism nearly always returns, making life long treatment necessary. In patients who do not have symptoms or signs of excess thyroid hormone thyroid function tests should be repeated every six months, with the recognition that tri-iodothyronine concentration may become raised before thyroxine does. ${ }^{3}$

\section{Authors' affiliations}

E H Hoogendoorn, M den Heijer, A R Hermus, Department of Endocrinology, University Medical Center Nijmegen, Netherlands 
A P J van Dijk, Department of Cardiology, University Medical Center Niimegen, Netherlands

\section{REFERENCES}

1 Ross DS. Subclinical thyrotoxicosis. In: Braverman LE, Utiger RD, eds. Werner and Ingbar's the thyroid. Philidelphia: J B Lippincott, 2000:1007-12.

2 Surks MI, Ocampo E. Subclinical thyroid disease. Am J Med 1996;100:217-23.

3 Toft AD. Clinical practice. Subclinical hyperthyroidism. N Engl J Med 2001;345:512-16

4 Andersen S, Pedersen KM, Bruun NH, et al. Narrow individual variations in serum $T(4)$ and $T(3)$ in normal subjects: a clue to the understanding of subclinical thyroid disease. J Clin Endocrinol Metab 2002;87:1068-72.

5 Bagchi N, Brown TR, Parish RF. Thyroid dysfunction in adults over age 55 years. A study in an urban US community. Arch Intern Med 1990;150:785-7.

6 Sawin CT, Geller A, Kaplan MM, et al. Low serum thyrotropin (thyroidstimulating hormone) in older persons without hyperthyroidism. Arch Intern Med 1991;151:165-8.

7 Canaris GJ, Manowitz NR, Mayor G, et al. The Colorado thyroid disease prevalence study. Arch Intern Med 2000;160:526-34.

8 Hollowell JG, Staehling NW, Flanders WD, et al. Serum TSH, T(4), and thyroid antibodies in the United States population (1988 to 1994): National Health and Nutrition Examination Survey (NHANES III). J Clin Endocrinol Metab 2002;87:489-99.

9 Volzke H, Ludemann J, Robinson DM, et al. The prevalence of undiagnosed thyroid disorders in a previously iodine-deficient area. Thyroid 2003;13:803-10.

10 Parle JV, Franklyn JA, Cross KW, et al. Prevalence and follow-up of abnormal thyrotrophin (TSH) concentrations in the elderly in the United Kingdom. Clin Endocrinol (Oxf) 1991;34:77-83.

11 Elte JW, Bussemaker JK, Haak A. The natural history of euthyroid multinodular goitre. Postgrad Med J 1990;66:186-90.

12 Faber J, Jensen IW, Petersen L, et al. Normalization of serum thyrotrophin by means of radioiodine treatment in subclinical hyperthyroidism: effect on bone loss in postmenopausal women. Clin Endocrinol (Oxf) 1998;48:285-90.

13 Biondi B, Palmieri EA, Lombardi G, et al. Effects of subclinical thyroid dysfunction on the heart. Ann Intern Med 2002;137:904-14.

14 Parle JV, Maisonneuve P, Sheppard MC, et al. Prediction of all-cause and cardiovascular mortality in elderly people from one low serum thyrotropin result: a 10-year cohort study. Lancet 2001;358:861-5.

15 Klein I, Ojamaa K. Thyroid hormone and the cardiovascular system. N Engl J Med 2001;344:501-9.

16 Woeber KA. Thyrotoxicosis and the heart. N Engl J Med 1992;327:94-8.

17 Biondi B, Fazio S, Carella C, et al. Cardiac effects of long term thyrotropinsuppressive therapy with levothyroxine. J Clin Endocrinol Metab 1993:77:334-8.

18 Biondi B, Fazio S, Cuocolo A, et al. Impaired cardiac reserve and exercise capacity in patients receiving long-term thyrotropin suppressive therapy with levothyroxine. J Clin Endocrinol Metab 1996:81:4224-8.

19 Biondi B, Fazio S, Carella C, et al. Control of adrenergic overactivity by betablockade improves the quality of life in patients receiving long term suppressive therapy with levothyroxine. J Clin Endocrinol Metab 1994;78:1028-33.

20 Fazio S, Biondi B, Carella C, et al. Diastolic dysfunction in patients on thyroidstimulating hormone suppressive therapy with levothyroxine: beneficial effect of beta-blockade. J Clin Endocrinol Metab 1995;80:2222-6.

21 Mercuro G, Panzuto MG, Bina A, et al. Cardiac function, physical exercise capacity, and quality of life during long-term thyrotropin-suppressive therapy with levothyroxine: effect of individual dose tailoring. J Clin Endocrinol Metab 2000;85:159-64.

22 Shapiro LE, Sievert R, Ong L, et al. Minimal cardiac effects in asymptomatic athyreotic patients chronically treated with thyrotropin-suppressive doses of Lthyroxine. J Clin Endocrinol Metab 1997;82:2592-5.

23 Biondi B, Palmieri EA, Fazio S, et al. Endogenous subclinical hyperthyroidism affects quality of life and cardiac morphology and function in young and middle-aged patients. J Clin Endocrinol Metab 2000;85:4701-5.

24 Faber J, Wiinberg N, Schifter S, et al. Haemodynamic changes following treatment of subclinical and overt hyperthyroidism. Eur J Endocrinol 2001;145:391-6.

25 Sgarbi JA, Villaca FG, Garbeline B, et al. The effects of early antithyroid therapy for endogenous subclinical hyperthyroidism in clinical and heart abnormalities. J Clin Endocrinol Metab 2003:88:1672-7.
26 Ladenson PW. Thyrotoxicosis and the heart: something old and something new. J Clin Endocrinol Metab 1993;77:332-3.

27 Tenerz A, Forberg R, Jansson R. Is a more active attitude warranted in patients with subclinical thyrotoxicosis? J Intern Med 1990;228:229-33.

28 Sawin CT, Geller A, Wolf PA, et al. Low serum thyrotropin concentrations as a risk factor for atrial fibrillation in older persons. N Engl J Med 1994;331:1249-52.

29 Auer J, Scheibner P, Mische T, et al. Subclinical hyperthyroidism as a risk factor for atrial fibrillation. Am Heart J 2001;142:838-42.

30 Baran DT, Braverman LE. Thyroid hormones and bone mass. J Clin Endocrinol Metab 1991;72:1182-3.

31 Faber J, Galloe AM. Changes in bone mass during prolonged subclinical hyperthyroidism due to L-thyroxine treatment: a meta-analysis. Eur J Endocrinol 1994;130:350-6.

32 Uzzan B, Campos J, Cucherat $M$, et al. Effects on bone mass of long term treatment with thyroid hormones: a meta-analysis. J Clin Endocrinol Metab 1996;81:4278-89.

33 Mudde AH, Reijnders FJ, Kruseman AC. Peripheral bone density in women with untreated multinodular goitre. Clin Endocrinol (Oxf) 1992:37:35-9.

34 Mudde AH, Houben AJ, Nieuwenhuijzen Kruseman AC. Bone metabolism during anti-thyroid drug treatment of endogenous subclinical hyperthyroidism. Clin Endocrinol (Oxf) 1994;41:421-4.

35 Cummings SR, Nevitt MC, Browner WS, et al. Risk factors for hip fracture in white women. Study of Osteoporotic Fractures Research Group. N Engl J Med 1995;332:767-73

36 Leese GP, Jung RT, Guthrie C, et al. Morbidity in patients on L-thyroxine: a comparison of those with a normal TSH to those with a suppressed TSH. Clin Endocrinol (Oxf) 1992;37:500-3.

37 Baver DC, Ettinger B, Nevitt MC, et al. Risk for fracture in women with low serum levels of thyroid-stimulating hormone. Ann Intern Med $2001 \cdot 134: 561-8$

38 Schlote B, Schaaf L, Schmidt R, et al. Mental and physical state in subclinical hyperthyroidism: investigations in a normal working population. Biol Psychiatry 1992;32:48-56.

39 Oomen HA, Schipperiin AJ, Drexhage HA. The prevalence of affective disorder and in particular of a rapid cycling of bipolar disorder in patients with abnormal thyroid function tests. Clin Endocrinol (Oxf) 1996;45:215-23.

40 Kalmiin S, Mehta KM, Pols HA, et al. Subclinical hyperthyroidism and the risk of dementia. The Rotterdam study. Clin Endocrinol (Oxf) 2000;53:733-7.

41 AACE Thyroid Task Force. American Association of Clinical Endocrinologists medical guidelines for clinical practice for the evaluation and treatment of hyperthyroidism and hypothyroidism. Endocr Pract 2002;8:457-69

42 Hermus AR, Huysmans DA. Treatment of benign nodular thyroid disease. N Engl J Med 1998;338:1438-47.

43 Vanderpump MP, Ahlquist JA, Franklyn JA, et al. Consensus statement for good practice and audit measures in the management of hypothyroidism and hyperthyroidism. The Research Unit of the Royal College of Physicians of London, the Endocrinology and Diabetes Committee of the Royal College of Physicians of London, and the Society for Endocrinology. BMJ 1996:313:539-44.

44 Helfand M, Redfern CC. Clinical guideline, part 2. Screening for thyroid disease: an update, American College of Physicians. Ann Intern Med 1998; 129:144-58.

\section{ANSWERS}

1. No, thyroid hormone therapy is the most common cause but multinodular goitre is the most common cause of endogenous subclinical hyperthyroidism. 2. Yes, five times as likely, according to the study by Auer et al. ${ }^{29}$ 3. Yes, according to the study by Bauer et al. ${ }^{37} 4$. No, there are conditions in which suppressive doses of thyroid hormone are thought to be advisory-for example, in patients who have been treated for differentiated thyroid carcinoma. 5. No, but an association has been found by Kalmijn et al between low TSH and the development of dementia. ${ }^{40}$ 